\title{
Remuneração do Trabalho Médico: Um Estudo Sobre Seus Sistemas e Formas em Hospitais Gerais de Belo Horizonte ${ }^{1}$
}

\section{Pay for Medical Labor: A Study of Systems and Forms of Payment in General Hospitals in Belo Horizonte, Brazil}

\author{
Mariangela L. Cherchiglia?
}

CHERCHIGLIA, M. L. Pay for Medical Labor: A Study of Systems and Forms of Payment in General Hospitals in Belo Horizonte. Brazil. Cad. Saúde Públ., Rio de Janeiro, 10 (1): 67-79, Jan/Mar, 1994.

A descriptive analysis of systems and forms of payment for medical labor was carried out based on an intentional sample of hospitals, according to preestablished criteria. Hospital administrators, physicians, and representatives of medical and entrepreneurial corporations were interviewed. The results were analyzed according to International Labour Organization (ILO) standards. The "Pay-for-Production System" was used exclusively in private hospitals, while the "Wage System" [based on units of time worked] prevailed in public ones. However, a major share of physicians from both private and public hospitals received different forms of payment simultaneously. "Pay-for-Results" was chosen by all the groups interviewed as the best should be carried out, since profissionals have shown great interest in it, and it also a valuable management tool.

Key words: Fees, Medical; Hospitals, General

\section{INTRODUÇÃO:}

A partir da Segunda Grande Guerra, observase um incremento significativo nos gastos e custos dos sistemas de atenção à saúde, particularmente no segundo hospitalar. No entanto, a crise econômica mundial dos anos 80 e as conseqüentes dificuldades de manutenção do padrão de financiamento público das políticas sociais adotadas nos anos do pós-guerra acompanharam-se de um farto receituário de medidas de ajuste, tanto na perspectiva da contenção de custos quanto no próprio corte de gastos (Abel Smith, 1984; Fuchs, 1986; Medici, 1989).

Assim, entre os vários modos de se controlar os gastos e reduzir os custos do setor saúde,

${ }^{1}$ Este trabalho é parte da Tese de Mestrado

"Remuneração do Trabalho Médico: Um Estudo sobre seus Sistemas e Formas em Hospitais Gerais de Belo Horizonte".CEPEAD/FACE/UFMG, setembro de 1993. ${ }^{2}$ Rua Tenente Anastácio de Moura, 1057/201. Belo Horizonte, MG, 30240-390, Brasil. podemos destacar as formas alternativas de remuneração dos médicos, bem como as buscas de aumento da produtividade.

O trabalho levanta questões sobre os sistemas e formas de remuneração do trabalho médico, um tema diversificado e controvertido, sobre o qual existem poucos estudos na área de saúde. $\mathrm{O}$ assunto é relevante nas teorias organizacionais, ganhando destaque neste momento de busca de aprimoramento gerencial pelas organizações de saúde. A escolha da categoria médica se deve à própria característica do trabalho em saúde, no qual o médico continua tendo papel dominante. Procuramos estudar a questão através da realização de uma análise descritiva dos sistemas e formas de remuneração do trabalho médico em hospitais gerais de Belo Horizonte, também apreendendo a percepção de três dos atores envolvidos - gerentes, médicos e representantes das categorias médica e empresarial -, sobre os mesmos. Assim, procuramos descobrir dados relevantes que viessem contribuir para o clareamento da utili- 
zação das formas de remuneração como um dos instrumentos de regulação do trabalho na área de saúde, em particular do setor hospitalar.

\section{SISTEMAS E FORMAS DE REMUNERAÇÃO}

Nosso estudo baseou-se em um referencial da teoria organizacional e em estudos sobre o trabalho médico. Entre esses destacamos os pressupostos da Organização Internacional do Trabalho (OIT) que tratam especificamente de sistemas e formas de remuneração.

Um sistema de remuneração são procedimentos para o pagamento do trabalho a determinadas pessoas ou grupos de pessoas, comportando formas variáveis. Os sistemas de remuneração e suas variadas formas, sejam quais forem os princípios que norteiem sua elaboração, são um meio de se controlar o comportamento dos membros da organização, com o objetivo de atingir uma estrutura orgânica que funcione com eficácia. Além disso, eles podem ser um modo de garantir que os trabalhadores realizem suas tarefas de tal maneira que a organização possa alcançar seus objetivos.

A OIT reconhece dois principais sistemas de remuneração: o Sistema de Remuneração por Resultado (RPR) e o Sistema de Remuneração por Tempo.

A remuneração por resultado (RPR) é um sistema no qual os ganhos em dinheiro dos trabalhadores variam, segundo regras preestabelecidas, com as mudanças medidas em seu resultado, entendido no seu sentido mais amplo, qual seja, resultado não somente quantitativo e direto, mas também qualitativo e indireto. $\mathrm{Na}$ RPR, a remuneração é efetivamente determinada depois que se registra o término da tarefa e depende do resultado alcançado. As várias formas, dentro de um sistema de RPR, podem ser classificadas em: individual (por tarefa/peça, por prêmios,), de grupo (por tarefa/peça, por prêmios) e de seção, departamento, ou empresas (por prêmios, redução de custos).

No Sistema de Remuneração por Tempo, o ganho é em função do tempo em que o trabalhador está à disposição de seu empregador. Não se leva em conta a variação do rendimento do trabalhador, o que lhe garante um ingresso estável e seguro todo mês. Isso não significa que o resultado não tenha nenhuma importância na remuneração por unidade de tempo. De certo modo, não somente a RPR, mas também a remuneração por tempo, relacionam esta com o rendimento. A diferença é que, na RPR, essa relação é explícita, formal e previamente estabelecida. As formas de remuneração, dentro de um sistema por tempo, podem ser classificadas em: "puras", remuneração fixa com resultado controlado e por mérito.

Nas diversas abordagens dadas ao papel da remuneração nas teorias motivacionais, ela é considerada não somente como uma variável econômica, mas um símbolo que representa as diversas recompensas psicológicas procuradas pelo indivíduo em seu ambiente de trabalho (Opsahl \& Dunnette, 1978; Lobos, 1979; Aquino, 1980, Nadler et al., 1983).

\section{FORMAS DE REMUNERAÇÃO DO TRABALHO MÉDICO}

Lee et al., (1990) discutem as diversas formas de remuneração do trabalho médico, na perspectiva de controle dos custos, dividindo-as por ato médico ou procedimento, por cada caso ou diagnóstico, por captação de pacientes e por tempo.

A remuneração por procedimento é o reembolso tradicional pela prestação de serviço (ato médico). O médico é pago por cada consulta, eletrocardiograma, endoscopia, cirurgia, etc. É um método de pagamento retrospectivo.

A remuneração por caso teria a mesma base do Diagnostic Related Groups (DRG), pelo qual o Medicare paga os hospitais e no qual baseia-se a tabela utilizada pelo Sistema Único de Saúde (SUS), do Brasil, para pagamento de internações hospitalares. O Sistema DRG classifica os pacientes de acordo com o diagnóstico principal, procedimento cirúrgico, complicações, outras condições mórbidas e procedimentos de enfermagem. Utiliza, também, um sistema de pesos e ajustes para fatores secundários; por exemplo, índice por região (Rice, 1991). No entanto, a possibilidade técnica de se utilizar a remuneração para médicos baseada na metodologia do DRG tem se mostrado difícil, principalmente para casos não cirúrgicos ou para pacientes ambulatoriais. 
Na remuneração por captação, o reembolso é literalmente por "cabeça". Implica uma unidade, que é o fator tempo, um certo pagamento por mês ou ano pelos inscritos sob o cuidado do médico. $\mathrm{O}$ pagamento por captação tende a ser mais prático para médicos que trabalham em ambulatório com uma população bem-definida para cada um, que passa a ser a referência.

$\mathrm{Na}$ remuneração por tempo, todos os outros fatores de resultado estão fora, permanecendo somente o fator tempo. O médico é empregado pelas horas que trabalha na clínica, um certo número de noites ou por tempo integral.

A crítica que se tem feito às virtudes de se utilizar formas de remuneração com unidades mais agregadas (por caso e captação) é o grande incentivo financeiro para diminuir os serviços oferecidos ao paciente (Geiger \& Krol, 1991). Por um lado, se a remuneração por procedimento é um incentivo "perverso" para o supertratamento, por outro, o pagamento por caso ou por captação é um incentivo "perverso" para o subtratamento. Na verdade, está se aplicando um princípio econômico para todas as formas de remuneração. Por uma dada unidade de pagamento, existe um incentivo financeiro para maximizar o número de unidades contadas, ao mesmo tempo que se miniminiza a quantidade de inputs que são componentes desta unidade. Em termos puramente econômicos, os médicos pagos por procedimento têm um incentivo para aumentar o número de consultas, mas limitar o tempo gasto com cada uma delas; aqueles que são pagos por caso têm um incentivo para diagnosticar e tratar mais casos, mas reduzir o número de consultas por caso; e os médicos reembolsados por captação podem ser motivados a aumentar o número de inscrição para poderem acumular muitos casos de pessoas doentes. A remuneração por tempo não tem um real incentivo financeiro para trabalhar em determinado nível, exceto o tempo. Por essa razão, têm sido utilizadas estratégias para aumentar o rendimento do médico, tais como a indexação de bônus por resultado ou o direto controle burocrático (Lee et al., 1990).

Os autores citados concluem que, na remuneração por unidades agregadas, a oportunidade de se ter incremento dos custos pelo aumento da quantidade produzida é menor. Por outro lado, o pagamento por unidades mais agregadas oferece menos recompensa financeira para o rendimento médico em termos do atual volume de serviços produzido. Nenhuma remuneração minado.por resultado garante um balanço ótimo entre a promoção de um incentivo financeiro e um desencorajamento da utilização ou produção de serviços. Dentro desta discussão de sistemas e formas de remuneração para os médicos, envolvendo incentivos financeiros, teríamos que considerar que esses seriam os únicos e mais importantes fatores de motivação do comportamento clínico do médico.

Como podemos perceber, as formas de remuneração do trabalho médico estariam inseridas dentro daqueles citados pela OIT (1985): Sistema de Remuneração por Resultados e Sistema de Remuneração por Tempo. Ainda que pese a variação no grau de agregação do produto, a remuneração por procedimento, por captação e por caso ou diagnóstico pertenceriam ao Sistema de Remuneração por Resultado. Do mesmo modo, a Remuneração por Tempo - com ou sem incentivos ao resultado - estaria no Sistema de Remuneração por Tempo.

\section{METODOLOGIA}

A partir de critérios previamente estabelecidos (tamanho do hospital, categoria, classificação e tipo de atividades) foi feita uma amostra intencional de nove hospitais - cinco hospitais privados e quatro públicos - e realizadas entrevistas com os gerentes e com os médicos que exerciam suas atividades nesses hospitais. Foram entrevistados também os representantes das corporações médica e empresarial. A autora entrevistou 8 entidades representantes das categorias médica e empresarial, 9 gerentes hospitalares e 60 médicos.

Para a análise de conteúdo foram construídos quadros comparativos com as percepções dos gerentes e médicos sobre as diversas formas de remuneração. A construção destes quadros se fez após a codificação das percepções, criandose categorias de significado semelhante (Hatt \& Goode, 1972).

Os sistemas e formas de remuneração foram sistematizados e definidos operacionalmente, adaptando-se os conceitos utilizados pela OIT (Quadro 1). 
QUADRO 1. Sistemas e Formas de Remuneração do Trabalho Médico

\begin{tabular}{|c|c|c|c|}
\hline \multicolumn{2}{|c|}{ Sistema de Remuneração por Resultado } & \multicolumn{2}{|c|}{ Sistema de Remuneração por Tempo } \\
\hline \multicolumn{2}{|c|}{ Produção } & \multirow{2}{*}{ Por Tempo } & \multirow{2}{*}{ Mista } \\
\hline Produto Agregado & Produto Não Agregado & & \\
\hline $\begin{array}{l}\text { Por diagnóstico ou } \\
\text { caso (Ex.: Tabela do } \\
\text { SUS, DRG) }\end{array}$ & $\begin{array}{l}\text { Por procedimento (Ex.: } \\
\text { Tabela AMB) }\end{array}$ & $\begin{array}{l}\text { Considera somente o } \\
\text { tempo disponível ao } \\
\text { empregador }\end{array}$ & $\begin{array}{l}\text { Inclui alguma medida de } \\
\text { resultado }\end{array}$ \\
\hline
\end{tabular}

Fonte: OIT, 1985. (Adaptado pela autora)

Na transposição dos sistemas de remuneração e suas formas estabelecidas pela OIT (1985) vamos perceber que a forma tradicional de remuneração por ato médico pode ser definida dentro do Sistema de Remuneração por Resultado como uma forma individual, por tarefa/peça, onde o que se mede e se retribui é a produção. Passamos a denominá-la Remuneração por Produção, entendida como a remuneração por unidades produzidas, sem levar em consideração qualquer outra variável, como gasto, custo ou qualidade. Na Remuneração por Produção pode haver variação no grau de agregação do produto remunerado, ou seja, a remuneração pode ser por caso ou diagnóstico (produto agregado) ou por atos ou procedimentos (produto não-agregado).

Dentro do Sistema de Remuneração por Tempo definimos duas formas prevalentes: a pura e a mista. Na forma pura por tempo, a remuneração é em função do tempo que o trabalhador está à disposição de seu empregador, não se considerando explicitamente nenhuma medida de resultado. Na mista, alguma medida de resultado é formalmente considerada, seja por grupo, seja individual. A forma de remuneração pura por tempo foi chamada Remuneração por Tempo, enquanto a remuneração mista por tempo foi denominada simplesmente Forma Mista.

\section{RESULTADOS}

Tabelas de Remuneração do Trabalho Médico

No levantamento de dados secundários foram encontradas duas tabelas que, em todos os hospitais da amostra, são referências para a remuneração do trabalho médico. A tabela do Sistema Único de Saúde (SUS), utilizada para pagamento hospitalar da rede pública e conveniada, e a tabela da Associação Médica Brasileira (AMB), empregada como referência para a remuneração dos serviços médicos, principalmente dos convênios. Todas as demais tabelas utilizadas são derivadas de uma dessas duas.

A tabela do SUS é baseada em critérios preestabelecidos, em que o valor é previamente determinado - pagamento prospectivo. Esses critérios foram definidos através do cálculo da média de cada procedimento ou ato realizado, que foram consolidados por grupos nosológicos, perfazendo aproximadamente $95 \%$ das internações praticadas (Rodrigues-Filho, 1990). É o denominado pagamento por caso ou diagnóstico, ou por produto agregado. $\mathrm{O}$ valor predeterminado é subdividido em cada componente do atendimento hospitalar: serviços hospitalares, serviços profissionais, serviços de apoio diagnóstico e terapêutico, sendo também fixada a taxa de permanência. Os serviços profissionais pelos quais os médicos são remunerados podem ser pagos de duas maneiras: diretamente pelo SUS ao médico (tipo 7) ou através do hospital, que posteriormente repassa ou remunera o médico por tempo (tipo 4). O tipo 4 é obrigatório para os hospitais públicos. Os valores da tabela do SUS são determinados centralmente, não se considerando os praticados pelo mercado. A remuneração médica pela tabela do SUS é o exemplo de Remuneração por Produção, em que o produto é agregado.

A tabela da AMB (1992) discrimina o valor 
de cada ato ou procedimento médico por meio de uma unidade denominada coeficiente de honorário $(\mathrm{CH})$, que é reajustada mensalmente pela inflação anterior. É uma forma de pagamento retrospectivo onde cada ato ou procedimento é remunerado pelo custo dos serviços faturados ou por produto não-agregado. Esta tabela mantém, portanto, um caráter neoliberal, aproximando-se da tradicional forma de pagamento direto do trabalho médico pelo paciente. Além disso, apresenta valores mais próximos dos praticados pelo mercado.

É pela tabela do SUS que a maior parte dos serviços médicos é paga. No entanto, é a tabela da AMB (1992) que vai ser utilizada como parâmetro, com maior frequiência, por quem remunera ou recebe por produção.

\section{Percepção das Entidades Representativas das Categorias Médica e Empresarial}

O discurso uniformizador das entidades representativas da categoria médica é o da remuneração "justa", não importando a forma. A forma justa tanto pode ser por produção, remunerada de acordo com a tabela da AMB (1992), quanto por tempo, desde que o salário seja "digno".

No entanto, pode-se perceber que elas se dividem na defesa de determinada forma de remuneração. Aí está refletida a essência ideológica e prática da fração da categoria médica que cada uma das entidades representa. Deve-se ressaltar, que das três entidades representantes da categoria médica, duas - a Associação Médica de Minas Gerais e o Conselho Regional de Medicina do Estado de Minas Gerais fazem defesa enfática da Remuneração por Produção. A terceira - o Sindicato dos Médi$\cos$ - defende a Remuneração por Tempo e julga importante que esta forma possa ser combinada com outras que considerem alguma medida de resultado (mista).

Para o Sindicato dos Hospitais e a Associação de Hospitais de Minas Gerais, a melhor forma de remuneração continua sendo a por ato médico ou por produção. Além de não ter os encargos trabalhistas, o médico fica vinculado ao hospital e os resultados são altos. A principal preocupação em relação a esta forma é o temor de que os médicos reclamem na Justiça do Trabalho o vínculo trabalhista com o hospital, alegando subordinação ao horário, ao diretor clínico, às normas hospitalares, etc. O pagamento por tempo é visto como uma equiparação aos serviços prestados pela rede pública. Além disso, nesta forma incide o pagamento de encargos trabalhistas, o que aumenta o custo do profissional.

Em relação às empresas que prestam serviço, a forma de remuneração preferida é por produção, pelos mesmos motivos apresentados pelas entidades representantes dos hospitais. No entanto, existe uma preocupação adicional, que é o controle do preço do trabalho médico. Este preço vai influir nos custos dos serviços prestados, com a conseqüente competitividade no mercado de assistência. Todas utilizam a tabela da AMB (1992) como referência da remuneração ao trabalho médico, apesar de estarem questionando judicialmente o uso da mesma.

\section{Sistemas e Formas de Remuneração nos Hospitais Estudados}

A maioria dos hospitais privados utiliza somente o Sistema por Resultado. Apenas um deles usa, além deste, o Sistema por Tempo (forma por tempo), numa proporção de $80 \%$ para o primeiro e $20 \%$ para o segundo. Os hospitais públicos só pagam pelo Sistema por Tempo. Metade deles utiliza duas formas, sendo que um deles remunera um maior número percentual de profissionais na forma por tempo, enquanto o outro emprega a forma mista. $\mathrm{Na}$ metade restante, em um dos hospitais é encontrada exclusivamente a forma mista e no outro, somente a forma por tempo.

\section{Perfil dos Profissionais e Formas de Remuneração}

A maioria dos métodos concentra-se na faixa de 5 a 19 anos de formatura. Quando consideradas as formas de remuneração em relação ao tempo de formatura (Tabela 1), nota-se que, nas formas por produção por tempo, há agregação semelhante a do total do número de profissionais. Na forma mista, a distribuição se faz mais homogênea por todas as faixas, observando-se um número expressivo de profissionais com menos de 4 anos de formatura em 
relação às duas outras formas. Na forma por tempo, a maior concentração ocorre no intervalo de 5 a 9 anos, enquanto na forma por produção esta concentração situa-se entre 15 e 19 anos.

Ressalta-se que, na amostra de hospitais estudados, a maioria dos médicos é do sexo masculino. Isso condicionou a distribuição de gênero da nossa amostra aleatória de profis- sionais entrevistados, que se divide em 18,3\% profissionais do sexo feminino e $81,7 \%$ do sexo masculino. Na Tabela 2, chama a atenção que a forma predominante para a remuneração das mulheres é por tempo, enquanto para os homens é por produção. A menor diferença é observada na forma por produção, sendo a forma mista menos prevalente para os dois grupos.

TABELA 1. Distribuição Percentual da Forma de Remuneração segundo o Tempo de Formatura dos Médicos no Hospital, Belo Horizonte, 1993.

\begin{tabular}{lccc}
\hline Tempo & \multicolumn{3}{c}{$\begin{array}{c}\text { Forma de Remuneração } \\
\text { de Formatura }\end{array}$} \\
\cline { 2 - 4 } (em anos) & Por Produção & Por Tempo & Mista \\
\hline até 4 & 4,0 & 5,0 & 20,0 \\
$5-9$ & 20,0 & 40,0 & 20,0 \\
$10-14$ & 20,0 & 20,0 & 13,3 \\
$15-19$ & 36,0 & 25,0 & 6,7 \\
$20-24$ & 4,0 & 5,0 & 13,3 \\
$25-29$ & 4,0 & 5,0 & 20,0 \\
mais de 30 & 12,0 & $\mathrm{z}$ & 6,7 \\
\hline Total & & 100,0 & 100,0 \\
\hline \hline
\end{tabular}

Fonte: Pesquisa direta

TABELA 2. Distribuição percentual por Sexo de acordo com a Forma de Remuneração, Belo Horizonte, 1993

\begin{tabular}{lcc}
\hline & \multicolumn{2}{c}{ Sexo (\%) } \\
\cline { 2 - 3 } & Feminino & Masculino \\
Formas & & \\
de Remuneração & 36,4 & 42,9 \\
\hline Por Produção & 45,4 & 30,6 \\
Por Tempo & 18,2 & 26,5 \\
Mista & 100,0 & 100,0 \\
\hline Total & & \\
\hline
\end{tabular}

Fonte: Pesquisa direta. 


\section{Sistemas e Formas de Remuneração do Trabalho Médico em Todas as Situações de Trabalho}

Considerando-se o Sistema de Remuneração, observa-se um discreto domínio do Sistema por Tempo (53\%), em detrimento do Sistema por Resultado (47\%).

Em todas as situações de trabalho destaca-se o elevado número percentual de profissionais que apresentam mais de uma forma de remuneração (Tabela 3). Também ocorre um predomínio da conjugação das formas por tempo e por produção, que é equivalente à soma de todas as outras formas conjugadas. Observa-se um discreto predomínio da forma por produção entre as formas puras, apresentando uma distribuição exatamente igual àquela encontrada no somatório das formas por tempo e mista. Além disso, nota-se o baixo percentual da forma mista.

\section{Percepção dos Gerentes e dos Médicos}

No tocante às vantagens das formas de remuneração, para a maioria dos gerentes hospitalares a principal vantagem do pagamento por produção é dar maior incentivo ao médico, no sentido de que ele trabalhe mais para poder receber mais, dedique uma maior quantidade do seu tempo e a qualidade do seu serviço ao hospital e aos seus pacientes, na perspectiva de obter um aumento da sua clientela. Neste aspecto, enfatiza-se esta forma de pagamento como a mais importante para vincular o médico à instituição, obtendo-se um melhor resultado. Em princípio, no pagamento por tempo haveria o vínculo, mas não necessariamente o estímulo ao resultado. Para os médicos não é perceptível uma tendência central, na medida em que as respostas se dividem entre obter melhor remuneração, receber pelo que se faz e ser esta a forma mais justa.

TABELA 3. Distribuição dos Profissionais de Acordo com a Forma de Remuneração em Todas as Situações, Belo Horizonte, 1993

\begin{tabular}{lcr}
\hline \multirow{2}{*}{ Formas } & \multicolumn{2}{c}{ Freqüência } \\
\cline { 2 - 3 } de Remuneração & Absoluta & Percentual \\
\hline \multirow{2}{*}{ Por Tempo } & 6 & 10,0 \\
Por Produção & 9 & 15,0 \\
Por Tempo e Por Produção & 22 & 36,7 \\
Mista & 3 & 5,0 \\
Mista e Por Tempo & 5 & 8,3 \\
Mista e Por Produção & 11 & 18,3 \\
Mista, Por Tempo e Por Produção & 4 & 6,7 \\
\hline Total & 60 & 100,0 \\
\hline \hline
\end{tabular}

Fonte: Pesquisa direta.

Há consenso entre gerentes e médicos que a principal vantagem da Remuneração por Tempo é a segurança que ela proporciona ao médico e à instituição, em termos de vínculo e direitos trabalhistas.

Não se nota grandes discrepâncias entre médicos e gerentes quanto às vantagens da forma mista. Além de possibilitar a segurança que a Remuneração por Tempo proporciona, ela também permite um ganho pelo resultado de seu trabalho.

Os gerentes e médicos concordam que a principal desvantagem da Remuneração por Produção é a insegurança, pela ausência de vínculo empregatício. Esta ausência representa para a instituição, ficar numa situação fragiliza- 
da, passível de sofrer processos judiciais trabalhistas. Para os médicos, não ter vínculo significa não poder adoecer, tirar férias ou se aposentar.

Em relação à desvantagem da Remuneração por Tempo, não existem discrepâncias significativas nas afirmações dos gerentes, que a consideram desestimulante à obtenção de resultado e à fixação do médico ao hospital. Para os médicos, há consenso de que a principal desvantagem é não ter controle sobre sua remuneração (Quadro 2).

$\mathrm{O}$ baixo valor que remunera o percentual referente ao resultado é apontado, por consenso, por gerentes e médicos, como a principal desvantagem da Remuneração Mista.
Para os gerentes, a relação entre a qualidade do serviço médico e a forma de remuneração é bastante evidente, divergindo consideravelmente os motivos apontados para se explicar esta fato. $\mathrm{Na}$ forma por produção haveria maior qualidade do trabalho médico. Esta percepção não é tão clara para os profissionais médicos, que, ao associarem a forma com o valor, relacionam a qualidade com o quanto é percebido pelo seu trabalho, não importando a forma como este é pago. Nesta situação, tendo uma remuneração "digna”, maior é a qualidade. Outras variáveis consideradas são as condições de trabalho e o caráter do profissional, influindo de modo significativo na qualidade.

QUADRO 2. Percepção das Vantagens e Desvantagens das Formas de Remuneração segundo Gerentes e Médicos, Belo Horizonte, 1993

\begin{tabular}{|c|c|c|c|}
\hline \multicolumn{2}{|r|}{ Forma de Remuneração } & Gerentes & Médicos \\
\hline $\begin{array}{l}\mathrm{V} \\
\mathrm{A} \\
\mathrm{N}\end{array}$ & $\begin{array}{l}\text { Remuneração } \\
\text { por Produção }\end{array}$ & $\begin{array}{l}\text { Incentivo à produção; } \\
\text { Fixação do médico à Instituição. }\end{array}$ & $\begin{array}{l}\text { Receber pelo que faz; } \\
\text { Forma justa; } \\
\text { Melhor remuneração. }\end{array}$ \\
\hline $\begin{array}{l}\mathrm{T} \\
\mathrm{A}\end{array}$ & $\begin{array}{l}\text { Remuneração } \\
\text { por Tempo }\end{array}$ & Segurança & Segurança \\
\hline $\begin{array}{l}E \\
N \\
S\end{array}$ & Remuneração Mista & $\begin{array}{l}\text { Seguranças; } \\
\text { Incentivo a produção. }\end{array}$ & $\begin{array}{l}\text { Segurança; } \\
\text { Complementação salarial; } \\
\text { Maior dedicação. }\end{array}$ \\
\hline $\begin{array}{l}\text { D } \\
\text { E } \\
\text { S }\end{array}$ & Remuneração por Produção & Insegurança & Insegurança \\
\hline $\begin{array}{l}\text { A } \\
N \\
\text { T } \\
\text { A }\end{array}$ & Remuneração por Tempo & $\begin{array}{l}\text { Desestimulante; } \\
\text { Pouco incentivo a fixação do } \\
\text { médico à Instituição. }\end{array}$ & $\begin{array}{l}\text { Não ter controle sobre o valor da } \\
\text { remuneração; } \\
\text { Não ganhar pelo que faz. }\end{array}$ \\
\hline $\begin{array}{l}\mathrm{U} \\
\mathrm{E} \\
\mathrm{N} \\
\mathrm{S}\end{array}$ & Remuneração Mista & $\begin{array}{l}\text { Pequeno valor do que é } \\
\text { remunerado como resultado. }\end{array}$ & $\begin{array}{l}\text { Ter direito somente quando se } \\
\text { está trabalhando; } \\
\text { pequeno valor do que é } \\
\text { remunerado como resultado. }\end{array}$ \\
\hline
\end{tabular}

Fonte: Pesquisa direta.

Tanto gerentes como médicos concordam que existe uma relação entre a forma de remuneração e o resultado. A Remuneração por Produção (individual ou por grupo) é um poderoso estímulo financeiro para se aumentar o número de atos médicos, trazendo maiores ganhos tanto para o hospital como para os médicos. No entanto, existem ressalvas, de ambas as partes, de que poder-se-ia criar distorções, como o crescimento de atos desnecessários e a 
conseqüente perda da qualidade. Destaca-se que a coincidência de respostas foi maior entre os médicos do que entre os gerentes (Quadro $3)$.

Buscou-se aprender, dos gerentes e dos médicos, o grau de satisfação dos médicos em relação àquela forma percebida no hospital. No entanto, esses fazem uma forte associação entre a satisfação do profissional com o valor, e não com a forma da remuneração. Entretanto, os médicos designam outros motivos (além do valor da remuneração), tais como prestígio, valorização profissional, reconhecimento, que são determinantes do nível de satisfação, independente da forma.

Ao se considerar de modo abstrato as diferentes formas, procurando saber quais delas seriam a mais satisfatória e a mais insatisfatória, não foi tão difícil para a maioria dos médicos chegar a uma resposta mais objetiva (Tabela 4).

QUADRO 3. Percepção da Relação entre Formas de Remuneração, Qualidade e Resultado do Trabalho Médico segundo Gerentes e Médicos, Belo Horizonte, 1993

\begin{tabular}{|c|c|c|}
\hline & Gerentes & Médicos \\
\hline $\begin{array}{l}\text { Forma de Remuneração x } \\
\text { Qualidade }\end{array}$ & Existe a relação & $\begin{array}{l}\text { Relacionam a qualidade a outras } \\
\text { variáveis }\end{array}$ \\
\hline $\begin{array}{l}\text { Forma de Remuneração x } \\
\text { Resultado }\end{array}$ & $\begin{array}{l}\text { Existe a relação: incentivar } \\
\text { o médico a aumentar o número } \\
\text { de atendimentos }\end{array}$ & $\begin{array}{l}\text { Existe a relação: quem ganha pelo } \\
\text { que produz tenta produzir mais }\end{array}$ \\
\hline
\end{tabular}

Fonte: Pesquisa direta.

TABELA 4. Distribuição Percentual das Formas de Remuneração Percebidas como a mais Satisfatória e a mais Insatisfatória pelos Médicos, Belo Horizonte, 1993.

\begin{tabular}{lcc}
\hline \hline $\begin{array}{l}\text { Formas } \\
\text { de Remuneração }\end{array}$ & $\begin{array}{c}\text { Mais Satisfatória } \\
(\%)\end{array}$ & $\begin{array}{c}\text { Mais Insatisfatória } \\
(\%)\end{array}$ \\
\hline Por Produção & 55,0 & 25,0 \\
Por Tempo & 20,0 & 58,3 \\
Mista & 16,7 & $\mathrm{z}$ \\
Todas & $\mathrm{z}$ & 3,3 \\
Nenhuma & 5,0 & 5,0 \\
\hline Total & $* 96,7$ & $* * 91,6$ \\
\hline
\end{tabular}

Fonte: Pesquisa direta.

* Um total de 3,3\% dos médicos não respondeu.

** Um total de 8,4\% dos médicos não respondeu. 
A forma por produção é apontada como a mais satisfatória, pelo mesmo motivo já apresentado como uma das vantagens desta forma, ou seja, receber pelo que produz. Destaca-se a pouca diferença entre a Remuneração por Tempo e a forma mista. No caso das duas últimas, tal como aconteceu com a anterior, as justificativas para a escolha coincidem com o que se apontou como vantagens. A segurança definiu a preferência pela forma por tempo. A opção pela forma mista se fez a partir da possibilidade de se conjugar o aumento da renda de acordo com a capacidade de trabalho, aliada à segurança proporcionada pela Remuneração por Tempo.

A ampla maioria dos médicos considera a forma por tempo como a mais insatisfatória, seguida da forma por produção, enquanto a forma mista sequer é citada. Mais uma vez percebe-se que é feita uma relação entre forma e valor, tanto em referência à Remuneração por Tempo quanto à Remuneração por Produção, sendo as duas mencionadas como insatisfatórias enquanto remunerações baixas. Especificamente na forma por tempo, também aponta-se a insegurança naqueles casos em que não há um vínculo empregatício.

\section{DISCUSSÃO DOS RESULTADOS}

A opção dos hospitais privados pela forma por produção relaciona-se com a visão de que é ela que incentiva o aumento do número de atendimentos, com maior qualidade, vinculando o profissional à instituição, obtendo-se dele maiores interesse e dedicação, além de reduzir ao mínimo a carga social. Estes são alguns dos motivos apontados pela OIT (1985) como vantagens da forma por produção.

Ainda que de modo incipiente, a maioria dos hospitais públicos utiliza uma forma semelhante à classificada pela OIT (1985) como Remuneração Fixa com Resultado Controlado Individual ou por Grupo. Nesta modalidade, a remuneração é feita segundo um contrato e está vinculada, com alguma fórmula, ao resultado medido no período anterior. Sob este aspecto, há concordância com a tendência mundial de se remunerar por tempo, associando-se uma medida de resultado. Esta tendência procura aliar as vantagens e eliminar as desvantagens que, isoladamente, cada uma das formas possui. Além disso, conforme já observado por Campos (1992), há nos serviços públicos de saúde a implantação de uma nova racionalidade administrativa, na qual tanto a busca de resultado quanto a adesão do médico à instituição têm merecido uma atenção especial por parte dos seus dirigentes. Aí evidencia-se a semelhança entre os discursos dos gerentes de ambas as categorias hospitalares.

A totalidade das entidades empresariais e a maioria das entidades corporativas médicas unem-se na preferência pela forma por produção. Essa união retrata a confluência de interesses entre hospitais e médicos, questão já ressaltada por Campos (1992). As transformações que têm ocorrido nas formas de remuneração nos hospitais públicas parecem influenciar a posição do Sindicato dos Médicos, que passa a admitir que alguma medida de resultado possa ser considerada.

As organizações de saúde e, de modo especial, os hospitais podem ser configuradas como organizações profissionais, nas quais os participantes têm maior vinculação às suas corporações profissionais do que aos objetivos institucionais (Blau e Scott, 1962; Etzioni, 1961). Este modo de organização dificulta a utilização de instrumentos gerenciais que possibilitam a adesão do médico à instituição. Ao mesmo tempo, facilita a composição dos interesses empresarias ou organizacionais com os de corporação médica, criando, no hospital, duas linhas de poder ou duas hierarquias distintas a do corpo clínico e a administrativa (Gonçalves, 1987; Campos, 1992).

Nos hospitais privados, a distinção entre essas duas linhas de poder evidencia-se quando a administração "abre mão" do controle do pagamento referente aos convênios e clientes particulares, que é feito diretamente ao próprio médico ou é gerenciado por ele.

Nos hospitais públicos, onde o sistema de remuneração é por tempo, o que acarreta não somente uma remuneração fixa, mas um tempo fixo, pode-se notar a dualidade de poder e hierarquia, e as dificuldades gerenciais ao se encontrar acordos negociados entre médicos e dirigentes para o cumprimento parcial da jornada de trabalho.

Aparentemente, é o ideal liberal que norteia 
a escolha da forma por produção como a mais satisfatória, e a Forma por Tempo como a mais insatisfatória, conforme já observado por Donnangelo (1975) e Cremesp (1983), segundo os quais esta forma aproximar-se-ia do sentido tradicional do trabalho médico. No entanto, devemos destacar também os baixos salários, os quais influenciam esta escolha.

A satisfação e a dedicação dos médicos em relação à remuneração nos hospitais em que trabalham adquirem um significado semelhante ao descrito por Lobos (1979). Para este autor, a remuneração, como uma das forças motivacionais mais importantes no trabalho, deve ser "requalificada", devendo ser correlacionada às suas características simbólicas, ao desempenho, e não ser impedimento a incentivos de ordem não econômica. Os médicos consideram outros fatores, como o prestígio, o reconhecimento e a valorização profissionais, além da possibilidade de ensino e aprendizagem. Essas variáveis, somadas ao valor da remuneração e não à sua forma, determinam o nível de dedicação e satisfação no trabalho.

A OIT (1985) considera que quanto mais o trabalhador acreditar que a remuneração pode ser legitimamente diferenciada, de acordo com o resultado, maior será a chance de se obter êxito ao se adotar a forma por produção. A forte associação que os médicos fazem entre formas de remuneração e resultado, reconhecendo a forma por produção como a mais justa e conveniente, encontra-se sintonizada com esta linha de pensamento. Esta percepção vem corroborar a utilização desta forma de hospitais privados, e de alguma medida que considere o resultado nos hospitais públicos, como um instrumento gerencial de aumento deste resultado.

\section{CONCLUSÃO}

As organizações vivem, na atualidade, um momento de busca de maior qualidade e de melhor resultado, com menor custo. Neste contexto, as formas de remuneração adquirem papel relevante para o gerenciamento organizacional. Essa busca pelo aprimoramento gerencial é também uma realidade para as organizações de saúde, especialmente as hospitalares.
Deste modo, pudemos constatar o interesse de gerentes e médicos sobre o tema. Os gerentes, por serem as formas de remuneração um dos mecanismos utilizados na regulação do trabalho. Os médicos, por "sofrerem" os efeitos destas formas. As entidades representantes das categorias, por defenderem os interesses corporativos dos segmentos que representam.

$\mathrm{O}$ fato de os médicos julgarem a forma por produção como a mais justa e satisfatória nos permite supor que as formas de remuneração que contemplam alguma medida de resultado podem representar um instrumento gerencial relevante a ser considerado pelas organizações hospitalares, especialmente as públicas, na busca de maiores eficiência e qualidade.

Pudemos constatar a multiplicidade de formas de remuneração vivenciadas por um mesmo profissional médico, refletindo não somente a ausência de um padrão homogêneo de mercado, mas também a procura desses profissionais em se resguardar das limitações de cada uma delas.

$\mathrm{O}$ enfoque que demos às formas de remuneração não nos afastou da consciência de que elas são apenas um dos aspectos da regulação do trabalho. De fato, ficou evidente no desenvolvimento deste estudo a importância de outros incentivos que não os exclusivamente monetários, inclusive a preocupação com a necessidade de se resgatar valores éticos. Este é um dos motivos da nossa crença na necessidade de estudos mais aprofundados, que busquem compreender melhor a motivação do médico no trabalho.

Ao sistematizar as formas de remuneração do trabalho médico em hospitais gerais de Belo Horizonte, esclarecendo alguns conceitos sobre elas e apreendendo a percepção dos três atores envolvidos, pensamos ter levantado hipóteses, tencionando criar condições para o desenvolvimento de futuras pesquisas sobre o tema. 


\section{RESUMO}

CHERCHIGLIA, M. L. Remuneração do Trabalho Médico: Um Estudo Sobre Seus Sistemas e Formas em Hospitais Gerais de Belo Horizonte. Cad. Saúde Públ., Rio de Janeiro, 10(1): 67-79, jan/mar, 1994.

Com o propósito de realizar uma análise descritiva dos sistemas e formas de remuneração do trabalho médico em hospitais gerais de Belo Horizonte e apreender a percepção de gerentes hospitalares, médicos e representantes das associações corporativas médicas e empresariais sobre os mesmos, foi feita uma amostra intencional de hospitais, conforme critérios previamente estabelecidos, e realizadas entrevistas com os profissionais ligados aos mesmos. Foram entrevistados, também, os representantes das corporações médica e empresarial. Na análise de dados, utilizando-se conceitos adaptados da Organização Internacional do Trabalho (OIT), encontrou-se o Sistema de Remuneração por Resultado, exclusivo dos hospitais privados, e o Sistema de Remuneração por Tempo, prevalente nos hospitais públicos. Foi constatado um elevado número de profissionais médicos que apresentam mais de uma forma de remuneração em todas as situações de trabalho. Os três atores envolvidos acreditam que a melhor forma de remuneração é aquela que considere alguma medida de resultado, visando maiores qualidade e resultado. A forma de remuneração por produção foi escolhida pelos médicos como a mais justa e satisfatória. $\mathrm{O}$ interesse pelo tema, demonstrado pelos profissionais, aliado à relevância do mesmo como um dos instrumentos de aperfeiçoamento gerencial, justifica mais estudos na área.

Palavras-Chave: Honorários Médicos; Hospitais Gerais.

\section{REFERÊNCIAS BIBLIOGRÁFICAS}

ABEL-SMITH, A., 1984. Cost containment in 12 European countries. World Health Statistic Quartely, 37: 351-363.

AQUINO, C. P., 1980. Administração de Recursos Humanos: Uma Introdução. São Paulo: Atlas.

ABM (Associação Médica Brasileira), 1992. Tabela de Honorários Médicos. São Paulo: Associação Médica Brasileira.

BLAU, P. M. \& SCOTT, W. R., 1962. Formal Organization: A Comparative Approach. San Francisco: Chandler, 1962.

CAMPOS, G. W. S., 1992. Reforma da Reforma: Repensando aSaúde. São Paulo: Hucitec.

CREMESP (Conselho Regional de Medicina do Estado de São Paulo), 1983. Condições do Exercício Profissional da Medicina na Área Metropolitana de São Paulo. São Paulo: CREMESP.(Relatório de Pesquisa)

DONNANGELO, M. C. F., 1975. Medicina e Sociedade: AO Médico e seu Mercado de Trabalho. São Paulo: Pioneira, 1975.

ETZIONI, A., 1961. A Comparative Analysis of Complex Organizations. New York: Free Press.

FUCHS, V. R., 1986. Has costcontainment gone too far? The Milbank Quartely, 64: 478-488.

GEIGER, W. J. \& KROL, R. A, 1991. Physician atitudes and behavior in response to changes in medicare reimbursement polices. The fournal Family Practices, 33: 244-248.

GONÇALVES, E. L., 1987. Administração de Recursos Humanos nas Instituições de Saúde. São Paulo: Pioneira.

HATT, P. K. \& GOODE, W. S., 1972. Métodos em Pesquisa Social, $4^{\mathrm{a}}$ ed., São Paulo: Nacional.

LEE, P. R.; GRUMBACH, K. \& JAMENSON, W. J., 1990. Physician payment in the 1990s: Factors that will shape the future. Annual Review of Public Health, 1: 297-318.

LOBOS, J. A., 1979. Administração de salários. In: Administração de Recursos Humanos, capítulo 7, pp. 253-285, São Paulo: Atlas.

MÉDICI, A. C., 1989. Saúde e crise na América Latina (impactos sociais e políticos de ajuste). Revista de Administração Pública, 23: 07-98.

NADLER, D. A. et al., 1983. Avaliação de desempenho e sistemas de recompensas. In: Comportamento Organizacional, (D. A. Nadler, org.), pp. 67-80, Rio de Janeiro: Campus. 
OIT (Oficina Internacional del Trajo), 1985. $L a$ Remuneración por Rendimento. Ginebra: OIT.

OPSAHL, R. \& DUNNETTE, M. D., 1978. O Papel da compensação financeira na motivação industrial. In: Comportamento Organizacional: Leituras selecionadas (J. A. Lobos, org.), pp. 131173, São Paulo: Atlas.
RICE. T.H., 1991. Physician reform in the United States. Yonsei Medical Fournal, 32: 101-107.

RODRIGUES-FILHO, J. , 1990. Métodos de pagamento hospitalar no Brasil. Revista de Administração Pública, 24: 78-86. 